\title{
Analysis on Multi Responses in Face Milling of Ammc Using Fuzzy-Taguchi Method
}

\author{
Madiri Samuel Sukumar*, Borra Vijay Sudheer Reddy, P. Venkataramaiah \\ Department of Mechanical Engineering, College of Engineering, Sri Venkateswara University, Tirupati, India \\ Email: ${ }^{*}$ mssukumar017@gmail.com
}

Received 26 May 2015; accepted 7 June 2015; published 10 June 2015

Copyright (C) 2015 by authors and Scientific Research Publishing Inc.

This work is licensed under the Creative Commons Attribution-NonCommercial International License (CC BY-NC).

http://creativecommons.org/licenses/by-nc/4.0/

(c) (i) (9) Open Access

\begin{abstract}
In this paper, Fuzzy-Taguchi Method has been used to identify the optimal combination of influential factors by analyzing the multi responses in the face milling. Milling experiment has been performed on AMMC (Aluminium Metal Matrix Composite), according to Taguchi orthogonal array (L27) for various combinations of influential parameters: speed, feed, depth of cut and coolant. Fuzzy logic is applied for the analysis of experimental response data of vibrations, temperature, surface roughness and resultant forces. The Fuzzy grade is calculated from this data and Fuzzy grade is optimized using Taguchi method in order to get the optimal parameter values, and also influence of parameters on individual responses is studied using Taguchi $\mathrm{S} / \mathrm{N}$ ratio analysis. This work is useful for analysis of machining parameters in face milling.
\end{abstract}

\section{Keywords}

Face Milling, AMMC, Fuzzy Logic, Taguchi S/N Ratio Analysis

\section{Introduction}

Conventional materials have the limitations in achieving good combination of strength, stiffness, toughness, density, etc. To overcome these limitations and to meet the ever increasing demand of modern day technology, composites are most promising materials in recent days. Metal matrix composites (MMCs) possess high strength, hardness, toughness, and good thermal resistance properties as compared to unreinforced alloys.

Milling is the process of machining flat, curved or irregular surfaces by feeding the work piece against a rotating cutter containing a number of cutting edges. The literature review related to machining of AMMC is presented in the following.

*Corresponding author.

How to cite this paper: Sukumar, M.S., Reddy, B.V.S. and Venkataramaiah, P. (2015) Analysis on Multi Responses in Face Milling of Ammc Using Fuzzy-Taguchi Method. Journal of Minerals and Materials Characterization and Engineering, 3, $255-270$. http://dx.doi.org/10.4236/immce.2015.34028 
Shivanand et al. (2004) [1] compared Powder Metallurgy method and stir casting method for producing the AMMC through testing of mechanical properties and concluded that stir casting method was best suitable for preparation of AMMC. Dalalah and Bataineh (2009) [2] presented a fuzzy logic approach to the selection of the best silicon crystal slicing technology. Fuzzy reasoning is used to model the expert's comprehension and uncertainty in the factors used in the decision criteria. Kuttolamadom et al. (2010) [3] studied the effects of machining feed on surface roughness in milling Al-6061. Increase the feed up until a cut-off surface roughness limit is reached and then increase the speed within the roughness range, to maximize productivity. Yazdi and Khorram (2010) [4] investigated the selection of optimal machining parameters for face milling operations in order to minimize the surface roughness and to maximize the material removal rate using RSM and ANN methods. Abuthakeer et al. (2011) [5] carried out a study to obtain the surface roughness and vibration responses were investigated at various parametric levels and combinations using LabVIEW software. On the completion of the experimental test, ANN is used to validate the results. Gunay et al. (2011) [6] focused on study of machining parameters on the cutting forces and surface roughness during face milling of Ti-6Al-4V alloy with carbide tools under dry conditions. Resultant cutting forces and surface roughness increased with an increase in feed rate, whereas decreasing with increase in cutting speed. Çalışkan et al. (2012) [7] showed the influence process parameters on the cutting forces $(\mathrm{Fx}, \mathrm{Fy}$, and Fz) and $\mathrm{Ra}$ in hard milling. According to the results of variance analysis, the cutting forces are the most sensitive to feed rate fz and then depth of cut. The cutting speed is only influential on Fx. Globocki Lakica et al. (2013) [8] carried out Experimental Research Using of MQL in Metal Cutting. The analysis shows that turning with MQL is a good alternative for conventional lubrication. Al-Zubaidi et al. (2013) [9] proposed a new multi objective optimization approach in the face milling. It is showed that the method provides a robust way of looking at the optimum parameter selection problems. Jatin (2013) [10] studied the effect of different machining on Surface Roughness in milling by Taguchi analysis. Low cutting speed should be used for long cutter life. High cutting speed and low feeds give best surface finishes. Venkata Ramaiah et al. (2013) [11] made an attempt to obtain optimum machining parameters for minimum cutting forces and cutting temperature by using Fuzzy Logic. It is showed that the method provides good results in machining of $\mathrm{Al} 6061$. Das et al. (2014) [12] investigated the application of traditional Taguchi method with fuzzy logic for multi objective optimization of the machining process of $\mathrm{Al}-5 \mathrm{Cu}$. Experimental results are demonstrated to present the effectiveness of this approach.

To address the lack of research in this issue, the present work has been done on face milling of AMMC with the following objectives:

1) To study the influence of machining parameters on multi responses;

2) To identify the optimal setting of milling process parameters (coolant, cutting speed, feed rate and depth of cut) for optimal responses: vibrations, temperature, surface roughness and resultant forces.

\section{Taguchi Orthogonal Array for Conducting Experiments}

In this experiment four process parameters at three levels have been considered are shown in Table 1.

$\mathrm{L}_{27}$ orthogonal array as shown in Table 2 has been chosen for conducting experiments. Experiments are performed according to this design and the values of surface roughness, resultant force, vibrations and temperature are recorded and their Normalized responses and response values are shown in Table 3.

\section{Milling of AMMC Material}

\subsection{Experimental Procedure}

Step by Step procedure used in the experimental work.

1) Keep the milling machine ready for performing the machining operation;

2) Connect the DAQ system to milling machine;

3) Connect the milling tool dynamometer to the milling machine;

4) Prepare the AMMC work piece sample and fix in machine vice;

5) Fix the milling cutter to an arbor and make machine ready for experiment;

6) Perform milling experiments as per Taguchi design on work piece for various combinations of process control parameters like coolant, spindle speed, feed and depth of cut;

7) Measure surface roughness with the help of a portable stylus-type Talysurf (Taylor Hobson, mitutyo); 
8) Measure forces such as thrust force, feed force, cross feed force by using milling tool dynamometer;

9) Measure vibrations by using accelerometer sensor (PCB Accelerometer having Sensitivity $100.5 \mathrm{mV} / \mathrm{g}$ ) and temperature by using temperature sensor (NI-9211Temperature Module) of LabVIEW based DAQ system.

\subsection{Measurement of Responses}

Experimental responses: surface roughness, vibrations, temperature and resultant forces are measured for different combinations of influential parameters. The measuring instruments and procedure is presented in the following.

Table 1. Process parameters and their levels.

\begin{tabular}{ccccc}
\hline Sl. No. & Parameters & Level 1 & Level 2 & Level 3 \\
\hline 1 & Coolant & Dry & Kerosene & Soluble oil \\
2 & Speed, rpm & 900 & 1120 & 1400 \\
3 & Feed, mm/rev & 315 & 500 & 800 \\
4 & Depth of cut, mm & 0.8 & 1.0 & 1.2 \\
\hline
\end{tabular}

Table 2. $\mathrm{L}_{27}$ orthogonal array.

\begin{tabular}{|c|c|c|c|c|}
\hline \multirow{2}{*}{ Exp. No. } & \multicolumn{4}{|c|}{ Process parameters } \\
\hline & Coolant & Speed (rpm) & Feed $(\mathrm{mm} / \mathrm{min})$ & Depth of cut (mm) \\
\hline 1 & Dry & 900 & 315 & 0.8 \\
\hline 2 & Dry & 900 & 500 & 1 \\
\hline 3 & Dry & 900 & 800 & 1.2 \\
\hline 4 & Dry & 1120 & 315 & 0.8 \\
\hline 5 & Dry & 1120 & 500 & 1 \\
\hline 6 & Dry & 1120 & 800 & 1.2 \\
\hline 7 & Dry & 1400 & 315 & 1 \\
\hline 8 & Dry & 1400 & 500 & 1.2 \\
\hline 9 & Dry & 1400 & 800 & 0.8 \\
\hline 10 & Kerosene & 900 & 315 & 1.2 \\
\hline 11 & Kerosene & 900 & 500 & 0.8 \\
\hline 12 & Kerosene & 900 & 800 & 1 \\
\hline 13 & Kerosene & 1120 & 315 & 1 \\
\hline 14 & Kerosene & 1120 & 500 & 1.2 \\
\hline 15 & Kerosene & 1120 & 800 & 0.8 \\
\hline 16 & Kerosene & 1400 & 315 & 1.2 \\
\hline 17 & Kerosene & 1400 & 500 & 0.8 \\
\hline 18 & Kerosene & 1400 & 800 & 1 \\
\hline 19 & Soluble oil & 900 & 315 & 1 \\
\hline 20 & Soluble oil & 900 & 500 & 1.2 \\
\hline 21 & Soluble oil & 900 & 800 & 0.8 \\
\hline 22 & Soluble oil & 1120 & 315 & 1.2 \\
\hline 23 & Soluble oil & 1120 & 500 & 0.8 \\
\hline 24 & Soluble oil & 1120 & 800 & 1 \\
\hline 25 & Soluble oil & 1400 & 315 & 0.8 \\
\hline 26 & Soluble oil & 1400 & 500 & 1 \\
\hline 27 & Soluble oil & 1400 & 800 & 1.2 \\
\hline
\end{tabular}


Table 3. Normalized responses.

\begin{tabular}{|c|c|c|c|c|c|c|c|c|}
\hline \multirow{2}{*}{$\begin{array}{l}\text { Exp. } \\
\text { No. }\end{array}$} & \multicolumn{4}{|c|}{ Responses } & \multicolumn{4}{|c|}{ Normalized responses } \\
\hline & $\begin{array}{l}\text { Resultant } \\
\text { force (Kgf) }\end{array}$ & $\begin{array}{l}\text { Vibrations } \\
\left(\mathrm{m} / \mathrm{sec}^{2}\right)\end{array}$ & $\begin{array}{c}\text { Temperature } \\
\left({ }^{\circ} \mathrm{C}\right)\end{array}$ & $\begin{array}{l}\text { Surface roughness } \\
(\mu \mathrm{m})\end{array}$ & $\begin{array}{l}\text { Resultant force } \\
\text { (Kgf) }\end{array}$ & $\begin{array}{l}\text { Vibrations } \\
\left(\mathrm{m} / \mathrm{sec}^{2}\right)\end{array}$ & $\begin{array}{l}\text { Temperature } \\
\left({ }^{\circ} \mathrm{C}\right)\end{array}$ & $\begin{array}{l}\text { Surface roughness } \\
\qquad(\mu \mathrm{m})\end{array}$ \\
\hline 1 & 7.28 & 8.29 & 35.1 & 0.26 & 0.84860 & 0.77143 & 0.8537 & 0.93631 \\
\hline 2 & 9.27 & 8.77 & 35.3 & 0.27 & 0.77821 & 0.63429 & 0.8469 & 0.92994 \\
\hline 3 & 10.82 & 8.94 & 37.1 & 0.53 & 0.72338 & 0.58571 & 0.7857 & 0.76433 \\
\hline 4 & 3.00 & 9.24 & 41.7 & 0.69 & 1.00000 & 0.50000 & 0.6293 & 0.66242 \\
\hline 5 & 7.87 & 9.48 & 43.9 & 1.15 & 0.82773 & 0.43143 & 0.5544 & 0.36943 \\
\hline 6 & 8.06 & 9.68 & 50.7 & 0.84 & 0.82101 & 0.37429 & 0.3231 & 0.56688 \\
\hline 7 & 12.88 & 10.35 & 56.4 & 0.59 & 0.65051 & 0.18286 & 0.1293 & 0.72611 \\
\hline 8 & 16.40 & 10.57 & 58.4 & 0.60 & 0.52600 & 0.12000 & 0.0612 & 0.71975 \\
\hline 9 & 8.66 & 10.69 & 60.2 & 0.58 & 0.79979 & 0.08571 & 0.0000 & 0.73248 \\
\hline 10 & 7.87 & 8.12 & 30.8 & 0.66 & 0.82773 & 0.82000 & 1.0000 & 0.68153 \\
\hline 11 & 8.77 & 8.43 & 31.5 & 0.52 & 0.79590 & 0.73143 & 0.9762 & 0.77070 \\
\hline 12 & 11.70 & 8.62 & 31.8 & 0.43 & 0.69225 & 0.67714 & 0.9660 & 0.82803 \\
\hline 13 & 23.02 & 8.97 & 39.2 & 0.16 & 0.29183 & 0.57714 & 0.7143 & 1.00000 \\
\hline 14 & 26.70 & 10.93 & 41.3 & 0.36 & 0.16166 & 0.01714 & 0.6429 & 0.87261 \\
\hline 15 & 24.35 & 9.67 & 41.7 & 0.65 & 0.24478 & 0.37714 & 0.6293 & 0.68790 \\
\hline 16 & 29.09 & 10.99 & 43 & 0.55 & 0.07711 & 0.00000 & 0.5850 & 0.75159 \\
\hline 17 & 27.29 & 9.69 & 43.7 & 0.51 & 0.14079 & 0.37143 & 0.5612 & 0.77707 \\
\hline 18 & 31.27 & 10.89 & 44.9 & 0.24 & 0.00000 & 0.02857 & 0.5204 & 0.94904 \\
\hline 19 & 4.90 & 7.87 & 33.6 & 1.20 & 0.93279 & 0.89143 & 0.9048 & 0.33758 \\
\hline 20 & 4.90 & 8.57 & 33.9 & 1.41 & 0.93279 & 0.69143 & 0.8946 & 0.20382 \\
\hline 21 & 4.90 & 7.49 & 35 & 0.81 & 0.93279 & 1.00000 & 0.8571 & 0.58599 \\
\hline 22 & 8.49 & 8.89 & 34.7 & 1.34 & 0.80580 & 0.60000 & 0.8673 & 0.24841 \\
\hline 23 & 7.55 & 7.65 & 37 & 1.09 & 0.83905 & 0.95429 & 0.7891 & 0.40764 \\
\hline 24 & 8.12 & 8.27 & 38.4 & 1.32 & 0.81889 & 0.77714 & 0.7415 & 0.26115 \\
\hline 25 & 16.55 & 9.87 & 37.5 & 1.73 & 0.52069 & 0.32000 & 0.7721 & 0.00000 \\
\hline 26 & 16.03 & 10.43 & 39.9 & 0.36 & 0.53909 & 0.16000 & 0.6905 & 0.87261 \\
\hline 27 & 16.58 & 10.99 & 41.6 & 0.50 & 0.51963 & 0.00000 & 0.6327 & 0.78344 \\
\hline
\end{tabular}

\subsubsection{Measurement of Surface Roughness}

The surface roughness values of the machined surface are measured in order to analyze the surface finish quality. Surface Roughness is measured with the help of Talysurf (Figure 1).

\subsubsection{Measurement of Vibrations Using PCB Accelerometer}

Spindle vibrations are measured using LabVIEW based DAQ. To measure the vibrations of the spindle, PCB Accelerometer (sensitivity $100.5 \mathrm{mv} / \mathrm{g}$ ) is placed on spindle as shown in Figure 2.

\subsubsection{Measurement of Temperature Using NI-9211 Thermocouple}

The temperature at the contact of tool and work piece is measured using LabVIEW software based NI-9211 temperature thermocouple. According to the design of experiments at various conditions Dry, Kerosene and soluble oil (Figure 3).

\subsubsection{Measurement of Cutting Force Using Milling Tool Dynamometer}

In order to measure the forces of thrust, feed and cross feed force, milling tool dynamometer (Figure 4) the resultant force [7] from these forces calculated. 


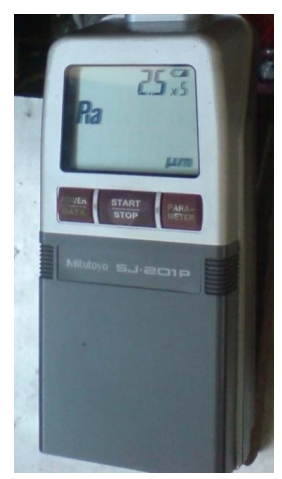

Figure 1. Talysurf (surface roughness measuring machine).

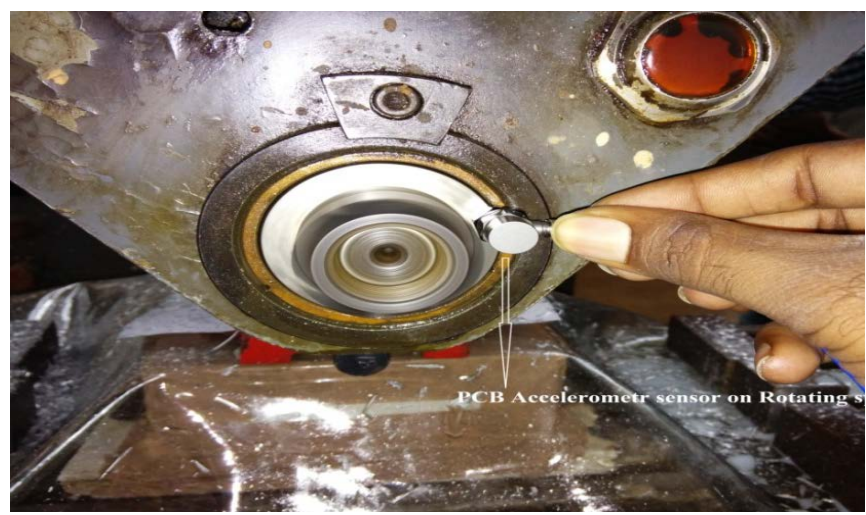

Figure 2. PCB accelerometer mounted on moving spindle.

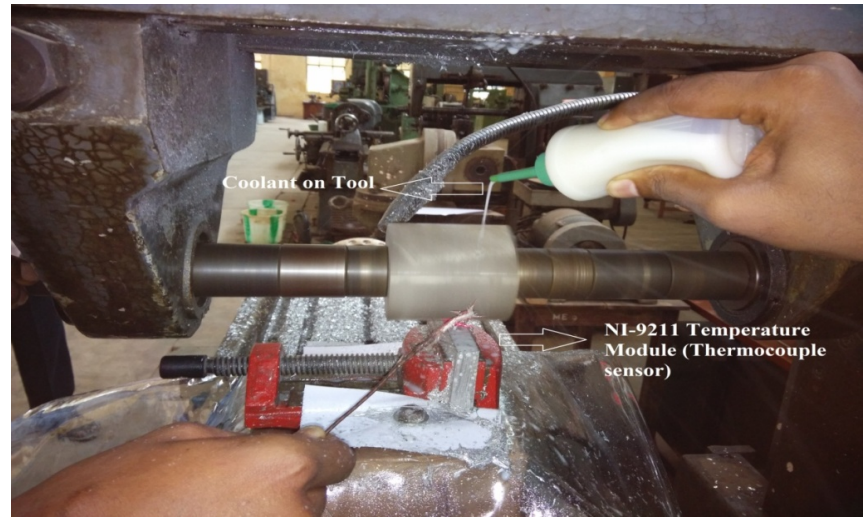

Figure 3. Thermocouple placed at contact of work piece and tool.

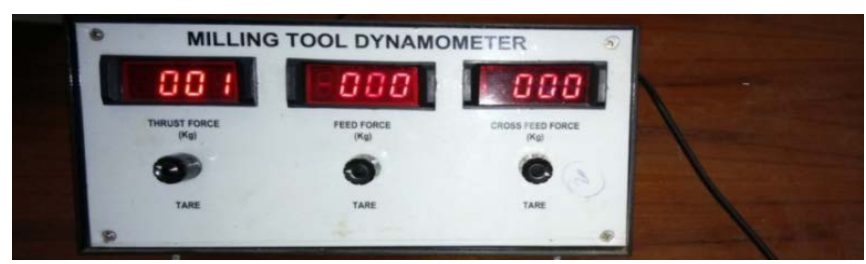

Figure 4. Milling tool dynamometer for measuring cutting forces.

\subsection{Data Normalization}

Data Normalization is done on data which has different range and unit in one data sequence may differ from the 
others. Data preprocessing is also necessary when the directions of the target in the sequences are different.

If the target data value characteristic is "smaller the better". The original sequence can be normalized using the Equation (1) as follows:

$$
x_{i}^{*}(k)=\frac{\max x_{i}^{o}(k)-x_{i}^{o}(k)}{\max x_{i}^{o}(k)-\min x_{i}^{o}(k)}
$$

where $i=1, \cdots, m ; k=1, \cdots, n . m$ is the number of experimental data items and $n$ is the number of parameters. $x_{i}^{o}(k)$ Denotes the original sequence, $x_{i}^{*}(k)$ the sequence after the data pre-processing, $\max x_{i}^{o}(k)$ the largest value of $x_{i}^{o}(k), \min x_{i}^{o}(k)$ the smallest value of $x_{i}^{o}(k)$, and $x^{o}$ is the desired value.

\section{Analysis of Multi Responses}

Deals with analysis of multi responses data shown in Table 3 and optimization of process parameters in milling of AMMC using Fuzzy logic and Taguchi analysis. And also influence of process parameters on individual responses is studied using Taguchi $\mathrm{S} / \mathrm{N}$ ratio analysis.

\subsection{Determinations of Optimum Process Parameters Using Fuzzy Logic}

The experimental data is analyzed using Fuzzy logic to determine optimum process parameters as in the following.

\subsubsection{Creation of Membership Functions}

Figures 5-8 shows the membership function for vibrations, Temperatures, Surface roughness input values in the process parameter.

Figure 9 shows the membership function selected to defuzzify the output (performance), calculated using the simplifying rules. The rules for process parameter for some rules are shown in Table 4.

Using more than three fuzzy sets would cause an explosion in the number of possible expressions. For the current case study 3 fuzzy sets and 4 inputs are considered. This results in a possible $34=81$ expressions. The five fuzzy sets used in the performance membership function are "very low", "low", "medium", "high", and "very high". Again, the trimf shape is employed to map the fuzzy sets. The use of the centroid defuzzification method

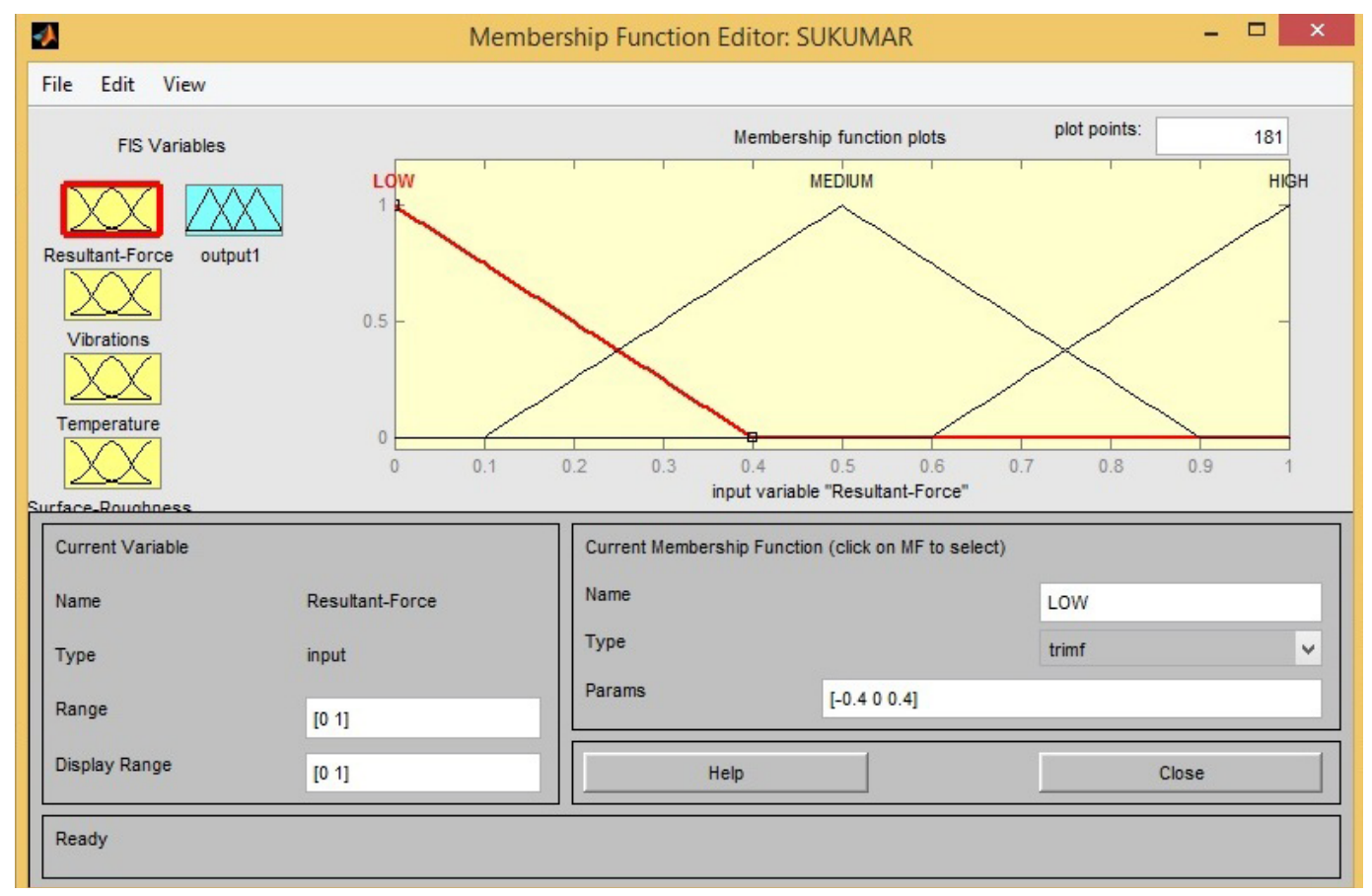

Figure 5. Membership function for resultant force. 


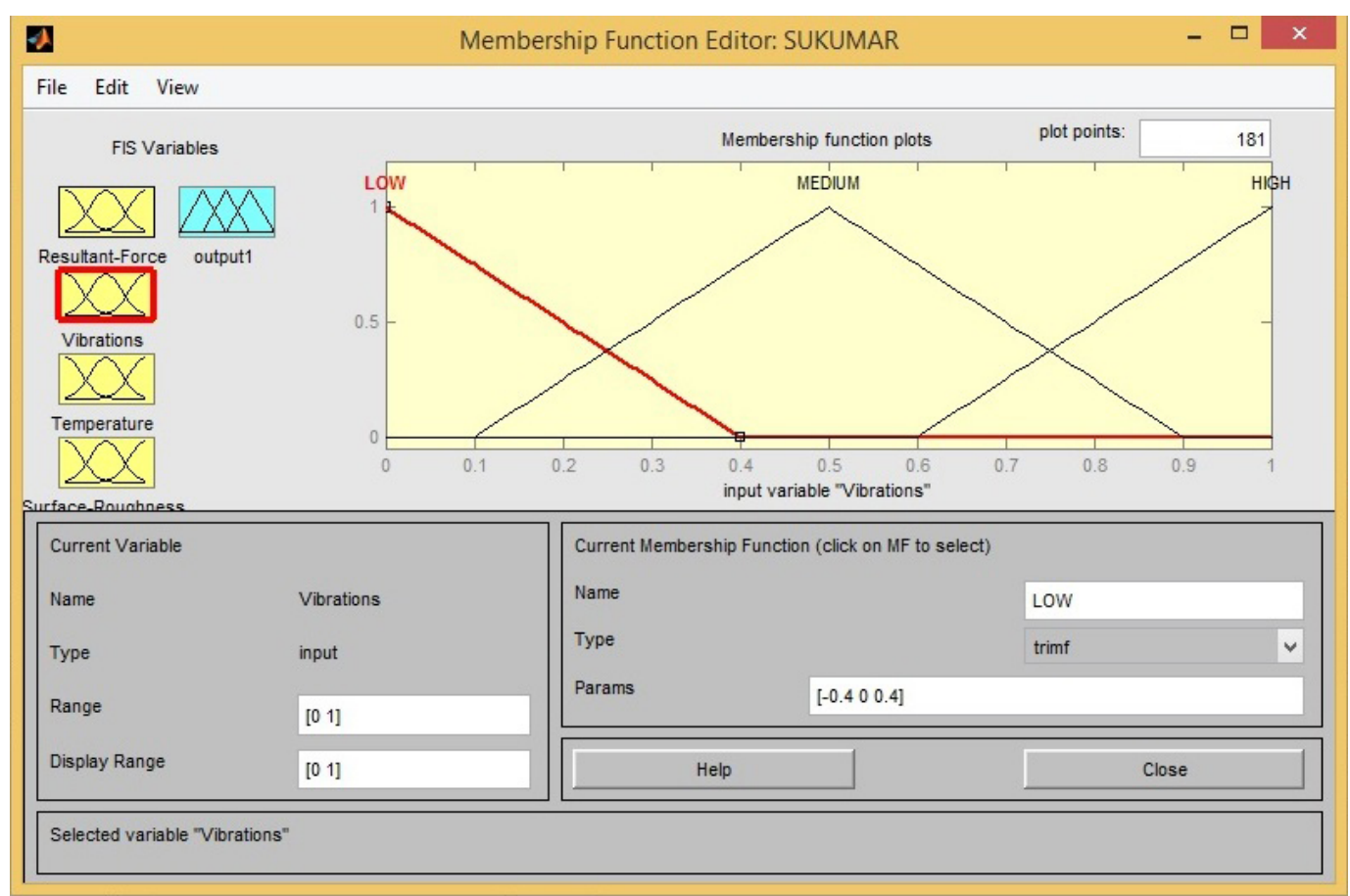

Figure 6. Membership functions for vibrations.

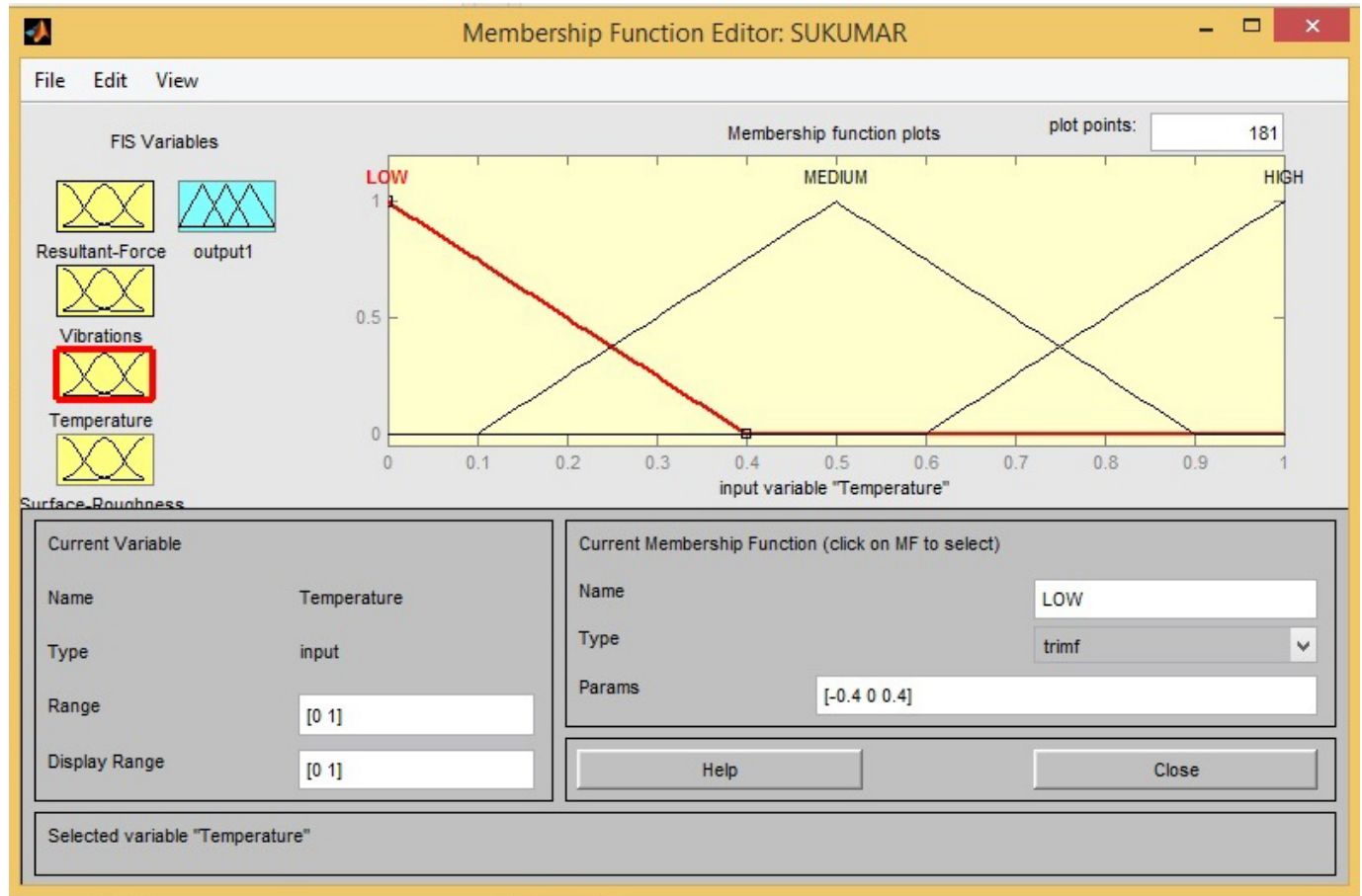

Figure 7. Membership functions for temperature.

is recommended as it results in a more smoothly shaped rule surface. In other words, the output performance index is less sensitive to slight variations in input values which occur near the fuzzy set overlaps. After the input and output membership functions are all defined and their fuzzy sets properly configured, the next step is to write the simplifying rules used to transform the input into output. As shown in the next section, this is the most crucial step in creating a fuzzy logic process parameter system. 


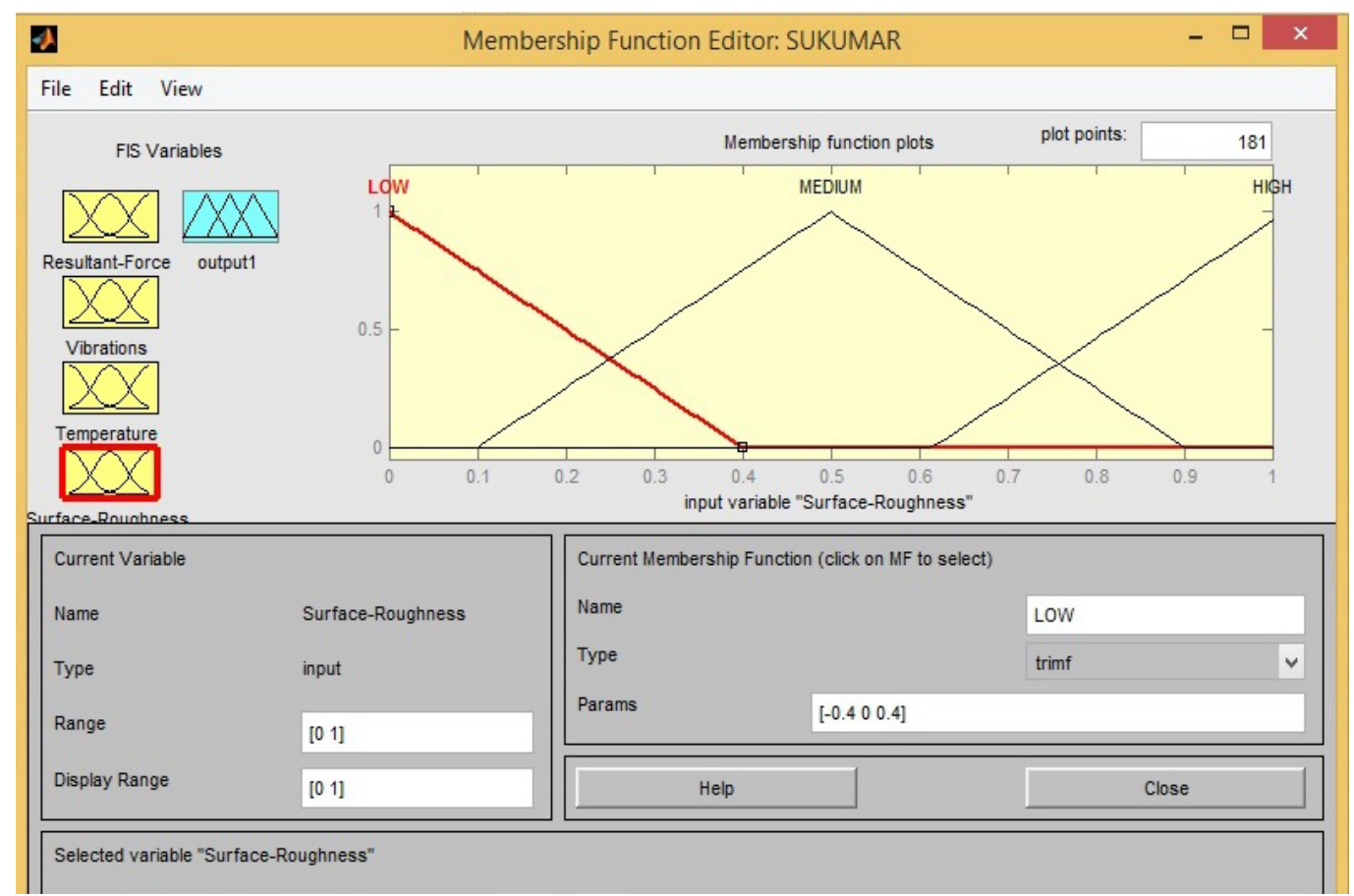

Figure 8. Membership functions for surface roughness.

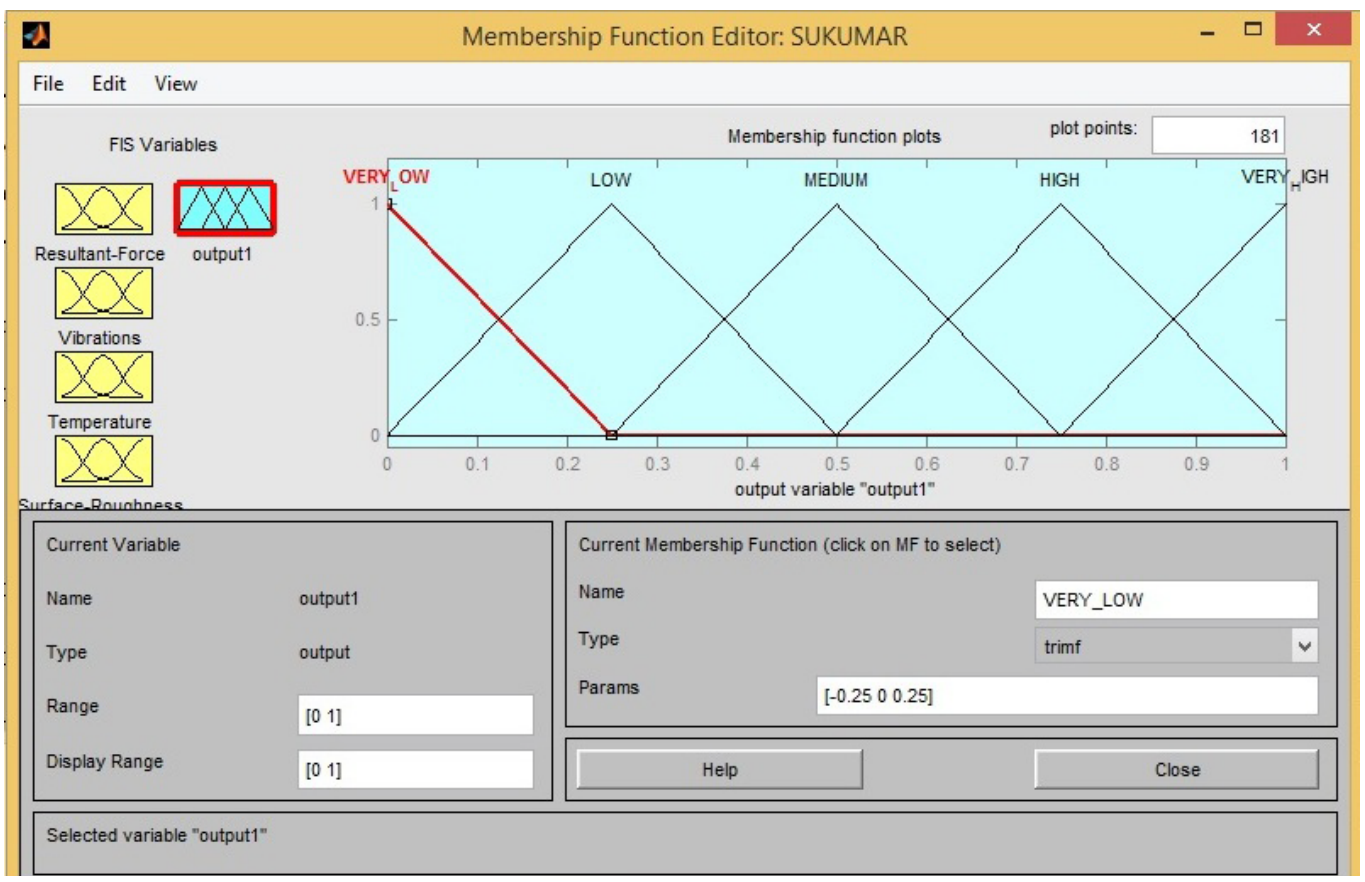

Figure 9. Membership functions for performance.

\subsubsection{Evaluation of Fuzzy Grade}

Fuzzy grade values are determined from Fuzzy logic using Fuzzy rules (Table 4) and normalizing data (Table 3). By using evaluation function of the MATLAB editor.

The evaluation function is: $b=$ [experimental data]; $a=$ readfis ("File name"), $t=$ evalfis $(b, a)$.

After executing above code, the output of FIS editor is obtained as shown in Table 5. These Fuzzy grade values are used for determining optimum parameter values by applying Taguchi techniques as in the following section. 
Table 4. Rules for process parameter.

\begin{tabular}{cccccccccccc}
\hline S. No. & & Resultant force & & Vibrations & & Temperature & & Surface roughness & Performance \\
\hline 1 & If & Low & And & Low & And & Low & And & Low & Then & Very high \\
2 & If & Low & And & Low & And & Low & And & Medium & Then & High \\
3 & If & Low & And & Low & And & Low & And & High & Then & Medium \\
4 & If & Low & And & Low & And & Medium & And & Low & Then & Very high \\
5 & If & Low & And & Low & And & Medium & And & Medium & Then & High \\
6 & If & Low & And & Low & And & Medium & And & High & Then & Medium \\
7 & If & Low & And & Low & And & High & And & Low & Then & High \\
8 & If & Low & And & Low & And & High & And & Medium & Then & Medium \\
9 & If & Low & And & Low & And & High & And & High & Then & Low \\
10 & If & Low & And & Medium & And & Low & And & Low & Then & Very high \\
- & - & - & - & - & - & - & - & - & - & - \\
- & - & - & - & - & - & - & - & - & - & - \\
- & - & - & - & - & - & - & - & - & - & - \\
78 & If & High & And & High & And & Medium & And & High & Then & Very low \\
79 & If & High & And & High & And & High & And & Low & Then & Medium \\
80 & If & High & And & High & And & High & And & Medium & Then & Low \\
81 & If & High & And & High & And & High & And & High & Then & Very low
\end{tabular}

Table 5. Fuzzy grade for normalized process parameters.

\begin{tabular}{|c|c|c|c|c|c|}
\hline \multirow{2}{*}{ Exp. No. } & \multicolumn{4}{|c|}{ Input parameters } & \multirow{2}{*}{ Fuzzy grade } \\
\hline & Resultant force (Kgf) & Vibrations $\left(\mathrm{m} / \mathrm{sec}^{2}\right)$ & Temperature $\left({ }^{\circ} \mathrm{C}\right)$ & Surface roughness $(\mu \mathrm{m})$ & \\
\hline 1 & 0.84860 & 0.77143 & 0.8537 & 0.93631 & 0.312 \\
\hline 2 & 0.77821 & 0.63429 & 0.8469 & 0.92994 & 0.3091 \\
\hline 3 & 0.72338 & 0.58571 & 0.7857 & 0.76433 & 0.3424 \\
\hline 4 & 1.00000 & 0.50000 & 0.6293 & 0.66242 & 0.3988 \\
\hline 5 & 0.82773 & 0.43143 & 0.5544 & 0.36943 & 0.541 \\
\hline 6 & 0.82101 & 0.37429 & 0.3231 & 0.56688 & 0.4524 \\
\hline 7 & 0.65051 & 0.18286 & 0.1293 & 0.72611 & 0.416 \\
\hline 8 & 0.52600 & 0.12000 & 0.0612 & 0.71975 & 0.4777 \\
\hline 9 & 0.79979 & 0.08571 & 0.0000 & 0.73248 & 0.5 \\
\hline 10 & 0.82773 & 0.82000 & 1.0000 & 0.68153 & 0.3263 \\
\hline 11 & 0.79590 & 0.73143 & 0.9762 & 0.77070 & 0.3286 \\
\hline 12 & 0.69225 & 0.67714 & 0.9660 & 0.82803 & 0.3252 \\
\hline 13 & 0.29183 & 0.57714 & 0.7143 & 1.00000 & 0.3893 \\
\hline 14 & 0.16166 & 0.01714 & 0.6429 & 0.87261 & 0.4943 \\
\hline 15 & 0.24478 & 0.37714 & 0.6293 & 0.68790 & 0.473 \\
\hline 16 & 0.07711 & 0.00000 & 0.5850 & 0.75159 & 0.5686 \\
\hline 17 & 0.14079 & 0.37143 & 0.5612 & 0.77707 & 0.447 \\
\hline 18 & 0.00000 & 0.02857 & 0.5204 & 0.94904 & 0.5144 \\
\hline 19 & 0.93279 & 0.89143 & 0.9048 & 0.33758 & 0.4091 \\
\hline 20 & 0.93279 & 0.69143 & 0.8946 & 0.20382 & 0.4605 \\
\hline 21 & 0.93279 & 1.00000 & 0.8571 & 0.58599 & 0.2908 \\
\hline 22 & 0.80580 & 0.60000 & 0.8673 & 0.24841 & 0.4837 \\
\hline 23 & 0.83905 & 0.95429 & 0.7891 & 0.40764 & 0.4157 \\
\hline 24 & 0.81889 & 0.77714 & 0.7415 & 0.26115 & 0.4906 \\
\hline 25 & 0.52069 & 0.32000 & 0.7721 & 0.00000 & 0.734 \\
\hline 26 & 0.53909 & 0.16000 & 0.6905 & 0.87261 & 0.3976 \\
\hline 27 & 0.51963 & 0.00000 & 0.6327 & 0.78344 & 0.4159 \\
\hline
\end{tabular}




\subsection{Taguchi Analysis}

Taguchi $\mathrm{S} / \mathrm{N}$ ratio analysis is performed on Fuzzy grade data shown in Table 6 using Minitab software and optimum parameter values are found (Table 7)and the main effects plot is shown in Figure 10.

From the results (Table 7 and Figure 11), optimum process parameters combination for Fuzzy grade is Speed 3-Coolant 3-Depth of cut 3-Feed 1

Which means

Speed at level $3(1400 \mathrm{rpm})$

Table 6. Factors and fuzzy grade for process parameters.

\begin{tabular}{|c|c|c|c|c|c|}
\hline S. No. & Coolant & Speed (rpm) & Feed (mm/min) & Depth of cut (mm) & Fuzzy grade \\
\hline 1 & Dry & 900 & 315 & 0.8 & 0.312 \\
\hline 2 & Dry & 900 & 500 & 1 & 0.3091 \\
\hline 3 & Dry & 900 & 800 & 1.2 & 0.3424 \\
\hline 4 & Dry & 1120 & 315 & 0.8 & 0.3988 \\
\hline 5 & Dry & 1120 & 500 & 1 & 0.541 \\
\hline 6 & Dry & 1120 & 800 & 1.2 & 0.4524 \\
\hline 7 & Dry & 1400 & 315 & 1 & 0.416 \\
\hline 8 & Dry & 1400 & 500 & 1.2 & 0.4777 \\
\hline 9 & Dry & 1400 & 800 & 0.8 & 0.5 \\
\hline 10 & Kerosene & 900 & 315 & 1.2 & 0.3263 \\
\hline 11 & Kerosene & 900 & 500 & 0.8 & 0.3286 \\
\hline 12 & Kerosene & 900 & 800 & 1 & 0.3252 \\
\hline 13 & Kerosene & 1120 & 315 & 1 & 0.3893 \\
\hline 14 & Kerosene & 1120 & 500 & 1.2 & 0.4943 \\
\hline 15 & Kerosene & 1120 & 800 & 0.8 & 0.473 \\
\hline 16 & Kerosene & 1400 & 315 & 1.2 & 0.5686 \\
\hline 17 & Kerosene & 1400 & 500 & 0.8 & 0.447 \\
\hline 18 & Kerosene & 1400 & 800 & 1 & 0.5144 \\
\hline 19 & Soluble oil & 900 & 315 & 1 & 0.4091 \\
\hline 20 & Soluble oil & 900 & 500 & 1.2 & 0.4605 \\
\hline 21 & Soluble oil & 900 & 800 & 0.8 & 0.2908 \\
\hline 22 & Soluble oil & 1120 & 315 & 1.2 & 0.4837 \\
\hline 23 & Soluble oil & 1120 & 500 & 0.8 & 0.4157 \\
\hline 24 & Soluble oil & 1120 & 800 & 1 & 0.4906 \\
\hline 25 & Soluble oil & 1400 & 315 & 0.8 & 0.734 \\
\hline 26 & Soluble oil & 1400 & 500 & 1 & 0.3976 \\
\hline 27 & Soluble oil & 1400 & 800 & 1.2 & 0.4159 \\
\hline
\end{tabular}

Table 7. Rank of process parameters for fuzzy grade.

\begin{tabular}{ccccc}
\hline Level & Coolant & Speed & Feed & Depth of cut \\
\hline 1 & 7.766 & 9.334 & 7.256 & 7.592 \\
2 & 7.516 & 6.794 & 7.456 & 7.649 \\
3 & 7.074 & 6.227 & 7.643 & 7.115 \\
Delta & 0.692 & 3.106 & 0.387 & 0.534 \\
Rank & 2 & 1 & 4 & 3 \\
\hline
\end{tabular}


Coolant at level 3 (Soluble oil)

Depth of cut at level $3(1.2 \mathrm{~mm})$

Feed at level $1(315 \mathrm{~mm} / \mathrm{rev})$

\subsection{Individual Response Analysis}

Taguchi $\mathrm{S} / \mathrm{N}$ ratio analysis is applied for data shown in Table 5 to study the influence of process parameters on individual responses. The results are shown in Figures 11-14 and Tables 8-11.

\subsubsection{S/N for Vibration versus Coolant, Speed, Feed and Depth of Cut}

From Figure 11 and Table 8, the optimum process parameters combination for individual response (Vibration) is Speed 3-Depth of cut 3-Coolant1, 2 -Feed 3

Which means

Speed at level 3 (1400 rpm)

Depth of cut at level $3(1.2 \mathrm{~mm})$

Coolant at level 1, 2 (Dry, Kerosene)

Feed at level $3(800 \mathrm{~mm} / \mathrm{rev})$

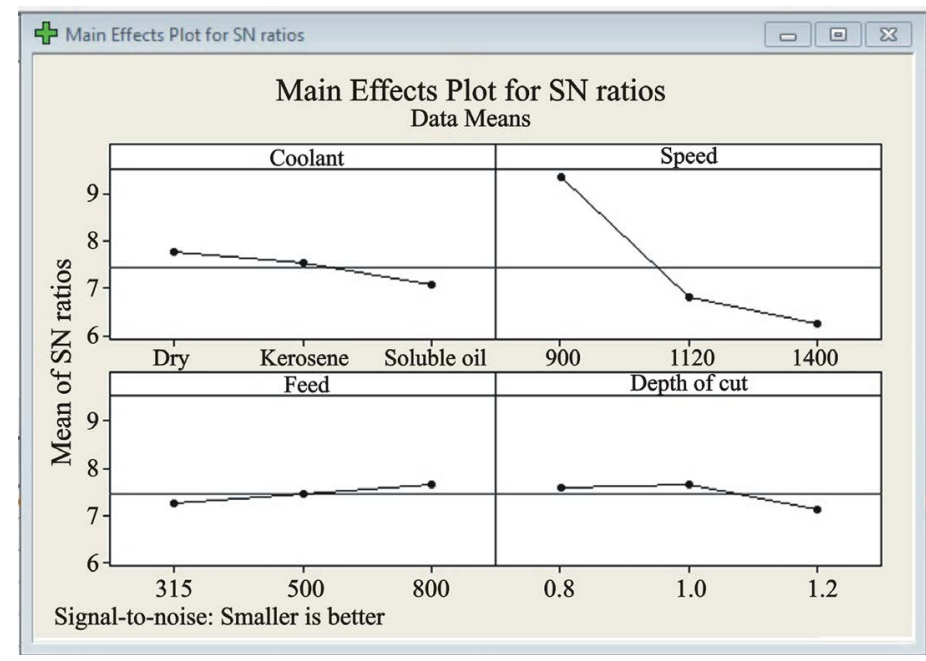

Figure 10. Main effects plot for vibration.

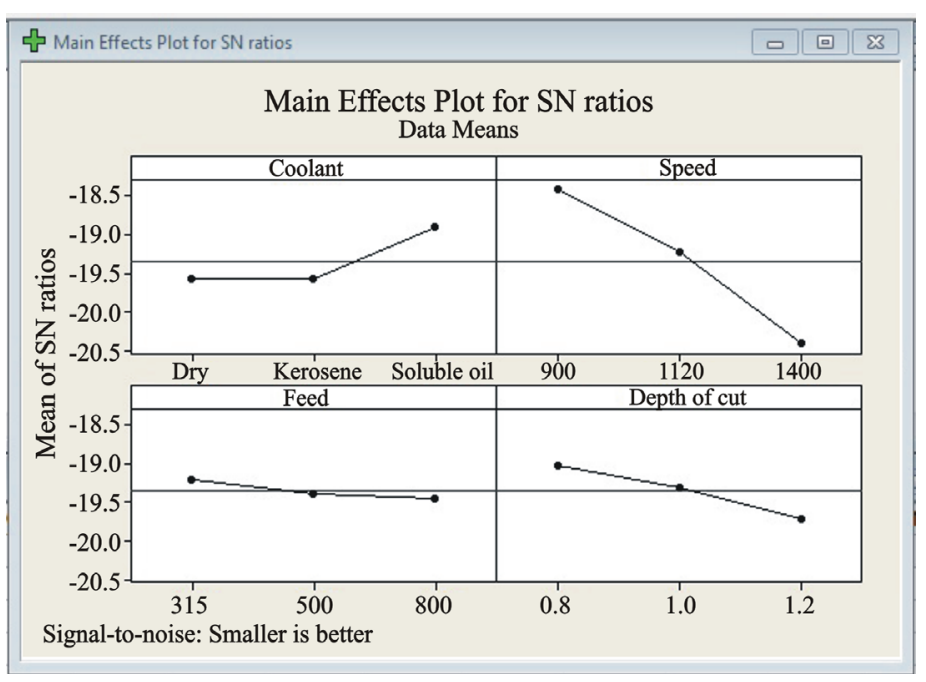

Figure 11. Main effects plot for fuzzy grade. 


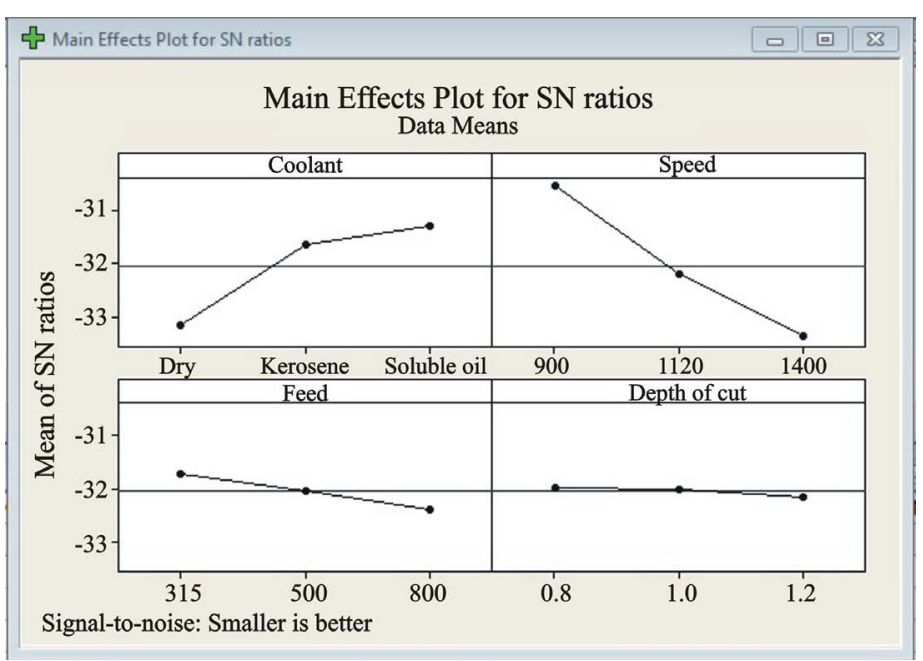

Figure 12. Main effects plot for temperature.

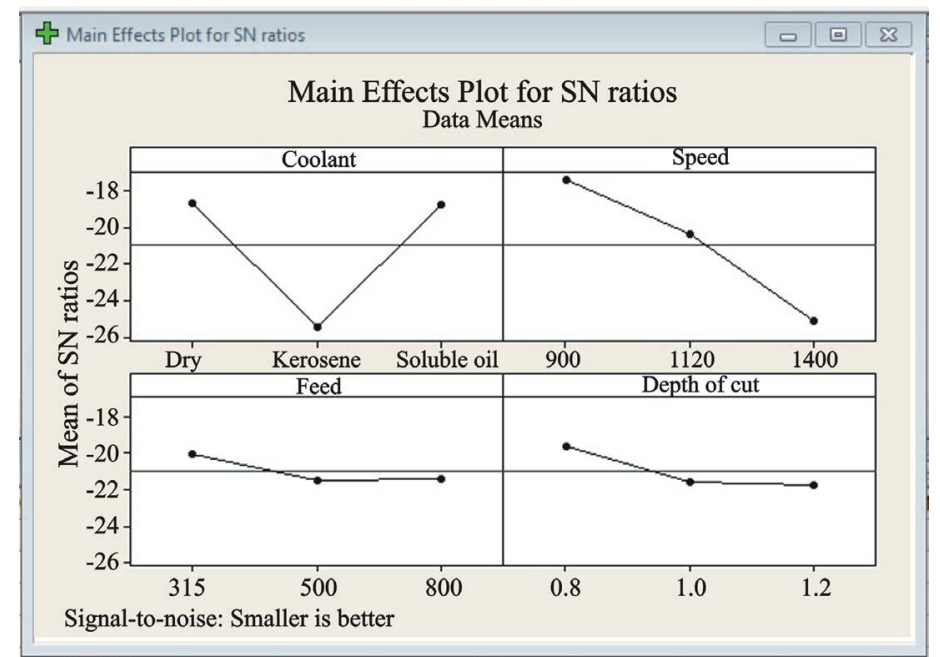

Figure 13. Main effects plot for resultant force.

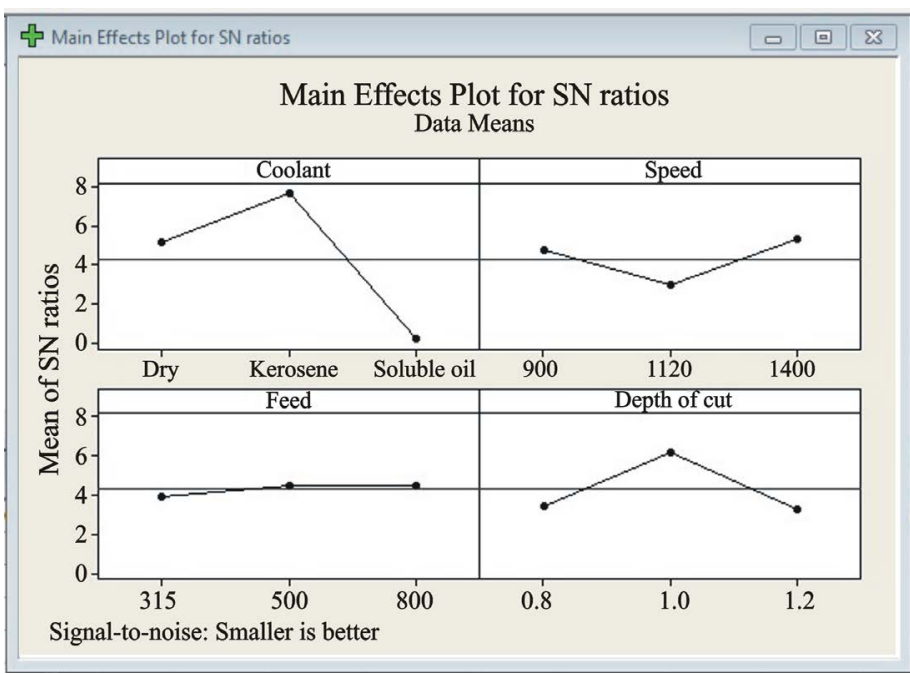

Figure 14. Main effects plot for surface roughness. 
Table 8. Rank of process parameters for vibration.

\begin{tabular}{ccccc}
\hline Level & Coolant & Speed & Feed & Depth of cut \\
\hline 1 & -19.58 & -18.42 & -19.20 & -19.03 \\
2 & -19.58 & -19.23 & -19.40 & -19.32 \\
3 & -18.90 & -20.41 & -19.46 & -19.72 \\
Delta & 0.68 & 2.00 & 0.26 & 0.69 \\
Rank & 3 & 1 & 4 & 2 \\
\hline
\end{tabular}

Table 9. Rank of process parameters for temperature.

\begin{tabular}{ccccc}
\hline Level & Coolant & Speed & Feed & Depth of cut \\
\hline 1 & -33.17 & -30.56 & -31.72 & -31.98 \\
2 & -31.66 & -32.20 & -32.02 & -32.00 \\
3 & -31.31 & -33.37 & -32.39 & -32.15 \\
Delta & 1.87 & 2.81 & 0.67 & 0.17 \\
Rank & 2 & 1 & 3 & 4 \\
\hline
\end{tabular}

Table 10. Rank of process parameters for resultant force.

\begin{tabular}{ccccc}
\hline Level & Coolant & Speed & Feed & Depth of cut \\
\hline 1 & -18.68 & -17.42 & -20.02 & -19.62 \\
2 & -25.50 & -20.38 & -21.46 & -21.56 \\
3 & -18.73 & -25.11 & -21.44 & -21.73 \\
Delta & 6.83 & 7.69 & 1.44 & 2.11 \\
Rank & 2 & 1 & 4 & 3 \\
\hline
\end{tabular}

Table 11. Rank of process parameters for surface roughness.

\begin{tabular}{ccccc}
\hline Level & Coolant & Speed & Feed & Depth of cut \\
\hline 1 & 5.0958 & 7.7189 & 3.9266 & 3.4718 \\
2 & 7.6211 & 2.9283 & 4.4599 & 6.1405 \\
3 & 0.1882 & 5.2580 & 4.5187 & 3.2929 \\
Delta & 7.4329 & 2.3297 & 0.5921 & 2.8476 \\
Rank & 1 & 3 & 4 & 2 \\
\hline
\end{tabular}

4.3.2. S/N for Temperature versus Coolant, Speed, Feed and Depth of Cut

From Figure 12 and Table 9, the optimum process parameters combination for individual response (Temperature)

Speed3-Coolant1-Feed3 -Depth of cut3

Which means

Speed at level 3 (1400 rpm)

Coolant at level 1 (Dry)

Feed at level $3(800 \mathrm{~mm} / \mathrm{rev})$

Depth of cut at level $3(1.2 \mathrm{~mm})$

4.3.3. S/N for Resultant Force versus Coolant, Speed, Feed and Depth of Cut

From Figure 13 and Table 10, the optimum process parameters combination for individual response (Resultant force) is

Speed3- Coolant2-- Feed2-Depth of cut3

Which means 
Speed at level $3(1400 \mathrm{rpm})$

Coolant at level 2 (Kerosene)

Feed at level $2(500 \mathrm{~mm} / \mathrm{rev})$

Depth of cut at level $3(1.2 \mathrm{~mm})$

\subsubsection{S/N for Surface Roughness versus Coolant, Speed, Feed and Depth of Cut}

From Figure 14 and Table 11, the optimum process parameters combination for individual response (Surface roughness) is

Coolant3- Depth of cut3 -Speed2- Feed1

Which means

Coolant at level 3 (Soluble oil)

Depth of cut at level $3(1.2 \mathrm{~mm})$

Speed at level $2(1120 \mathrm{rpm})$

Feed at level $1(315 \mathrm{~mm} / \mathrm{rev})$

\subsection{Conformation Test Results}

Conformation experiment is conducted for optimum parameter combination and the values of Vibrations (shown in Figure 15 and Figure 16), Temperature (shown in Figure 17 and Figure 18), surface roughness, and resultant forces are recorded (Table 12).

According to Fuzzy based Taguchi $\mathrm{S} / \mathrm{N}$ ratio analysis, the optimal combination of input parameters is Coolant $=$ Soluble oil

Speed $=1400 \mathrm{rpm}$

Depth of cut $=1.2 \mathrm{~mm}$

Feed $=315 \mathrm{~mm} / \mathrm{rev}$

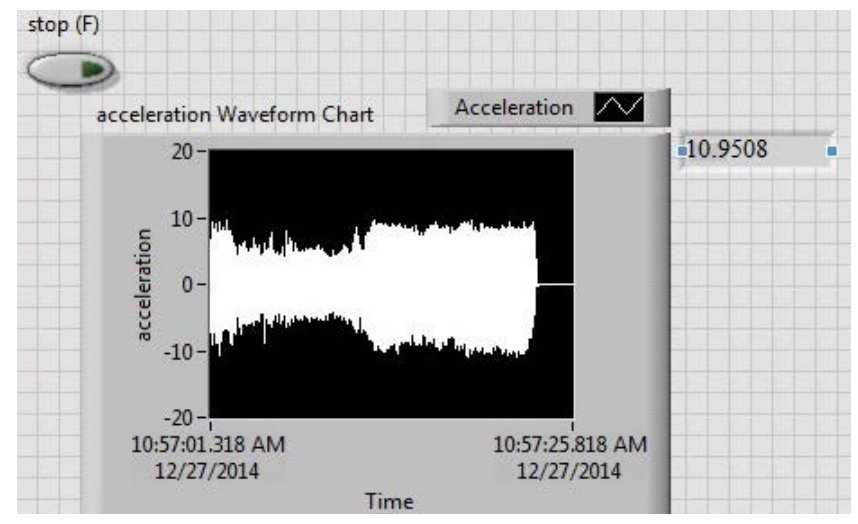

Figure 15. Lab VIEW front panel of acceleration(output).

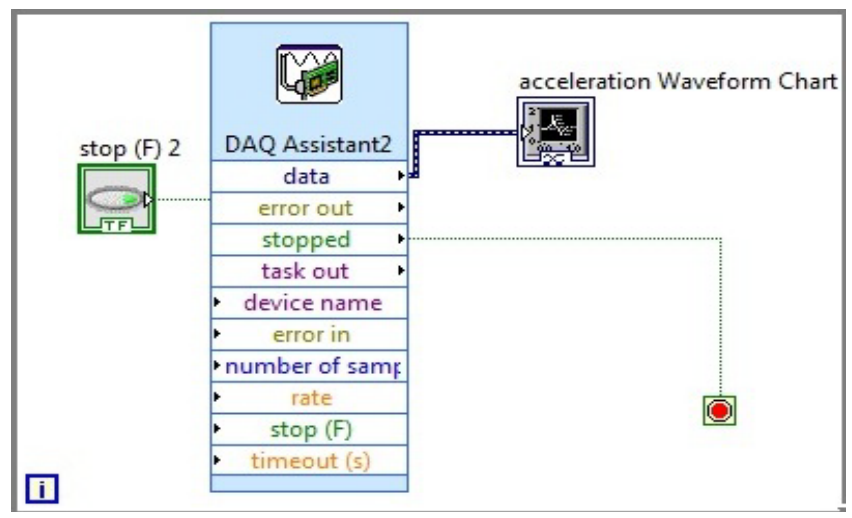

Figure 16. Lab VIEW block diagram of acceleration. 


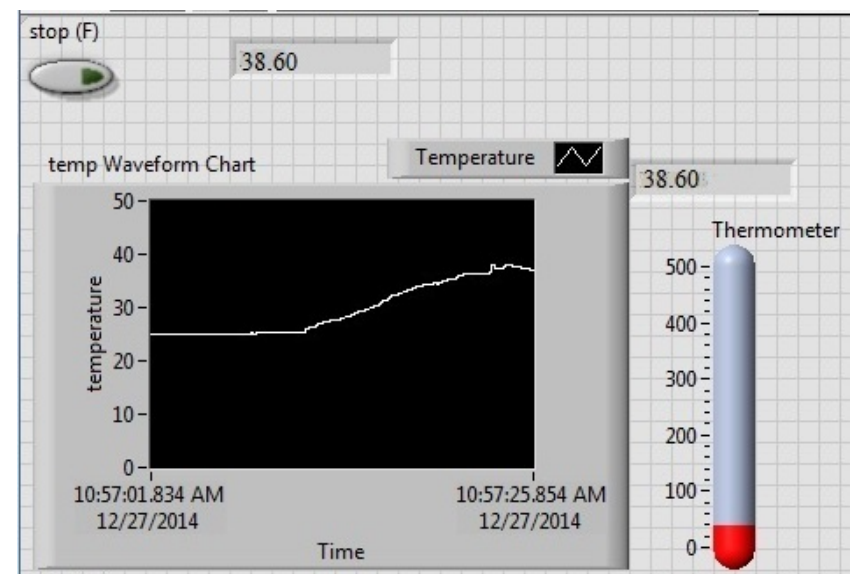

Figure 17. Lab VIEW front panel of temperature(output).

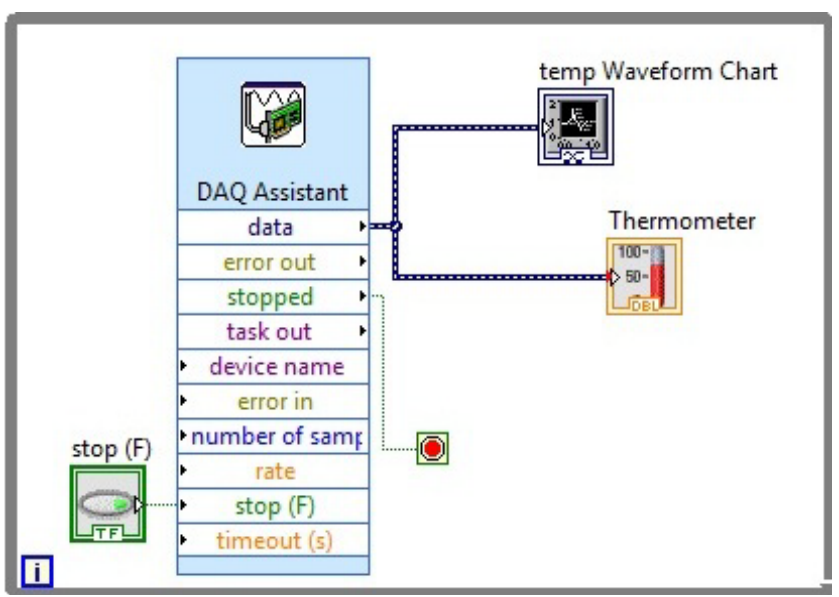

Figure 18. Lab VIEW block diagram of temperature.

Table 12. Experimental results.

\begin{tabular}{cccccccc}
\hline Coolant & $\begin{array}{c}\text { Speed } \\
(\mathrm{rpm})\end{array}$ & $\begin{array}{c}\text { Feed } \\
(\mathrm{mm} / \mathrm{min})\end{array}$ & $\begin{array}{c}\text { Depth of cut } \\
(\mathrm{mm})\end{array}$ & $\begin{array}{c}\text { Resultant force } \\
(\mathrm{Kgf})\end{array}$ & $\begin{array}{c}\text { Vibrations } \\
\left(\mathrm{m} / \mathrm{sec}^{2}\right)\end{array}$ & $\begin{array}{c}\text { Temperature } \\
\left({ }^{\circ} \mathrm{C}\right)\end{array}$ & $\begin{array}{c}\text { Surface roughness } \\
(\mu \mathrm{m})\end{array}$ \\
\hline Soluble oil & 1400 & 315 & 1.2 & 19.28 & 10.95 & 38.6 & 0.52 \\
\hline
\end{tabular}

\section{Conclusions}

The influence of machining parameters on the multi responses is studied and the following conclusions are drawn from the results.

1) The order of influenced parameters found from Fuzzy-Taguchi analysis is as follows:

- Speed (most influential);

- Coolant (moderately influential);

- Depth of cut (least influential);

- Feed (very least influential).

2) Taguchi analysis shows that speed has more influence on vibrations, forces and temperature and that coolant has more influence on surface roughness.

3) Confirmation test has been conducted and results are satisfactory.

However, this work can be extended further by considering the followings:

- Accuracy of predictions will be enhanced by generating more experimental data for training;

- Tools with coated materials like Titanium, diamond, etc., are to be used in order to get the best results.

- Use of CNC machines is for automatic adjustments of parameter values. 


\section{References}

[1] Shivanand, H.K., Benal, M.M., Sharma, S.C. and Govindraju, N. (2004) Comparative Studies on Mechanical Properties of Aluminium Based Hybrid Composites Cast by Liquid Melt Technique and P/M Route. Materials Processing for Properties and Performance, 3, 57-60.

[2] Dalalah, D and Bataineh, O. (2009) A Fuzzy Logic Approach to the Selection of the Best Silicon Crystal Slicing Technology. Expert Systems with Applications, 36, 3712-3719. http://dx.doi.org/10.1016/j.eswa.2008.02.020

[3] Kuttolamadom, M.A., Hamzehlouia, S. and Laine Mears, M. (2010) Effect of Machining Feed on Surface Roughness in Cutting 6061 Aluminum. International Center for Automotive Research, Clemson university, South Carolina, United state, 2010-01-0218.

[4] Soleymani Yazdi, M.R. and Khorram, A. (2010) Modeling and Optimization of Milling Process by Using RSM and ANN Methods. International Journal of Engineering and Technology, 2, 474-480. http://dx.doi.org/10.7763/IJET.2010.V2.167

[5] Abuthakeer, S.S., Mohanram, P.V. and Mohankumar, G. (2011) The Effect of Spindle Vibration on Surface Roughness of Workpiece in Dry turning using ANN. International Journal of Lean Thinking, 2.

[6] Gunay, M., Kacal, A. and Turgut, Y. (2011) Optimization of Machining in Milling of Ti-6Al-4V Alloy using Taguchi method. e-Journal of New World Sciences Academy, 6, Article No. 1A0165.

[7] Çalışkan, H., Kurbanoğlu, C., Panjan, P. and Kramar, D. (2012) Investigation of the Performance of Carbide Cutting Tools with Hard Coatings in Hard Milling Based on the Response Surface Methodology. The International Journal of Advanced Manufacturing Technology, 66, 883-893. http://dx.doi.org/10.1007/s00170-012-4374-y

[8] Globočki Lakić, G., Sredanović, B., Kramar, D., Nedić, B. and Kopač, J. (2013) Experimental Research Using of MQL in Metal Cutting. Tribology in Industry, 35, 276-285.

[9] Al-Zubaidi, S. Ghani, J.A., Hassan, C. and Haron, C. (2013) Optimization of Cutting Conditions for End Milling of TiAL4V by Using a Gravitational Search Algorithm. Mechanica, 48, 1710-1715.

[10] Jatin, P.S. (2013) Effect of Machining Parameters on Output Characteristics of CNC Milling Using Taguchi Optimization Technique. IJEBEA 13-335, 2013

[11] Venkata Ramaiah, P., Rajesh, N. and Dharma Reddy, K. (2013) Determination of Optimum Influential Parameters in Turning of Al6061 Using Fuzzy Logic. IJIRSET, 2.

[12] Das, B., Roy, S., Rai, R.N. and Saha, S.C. (2014) Surface Roughness of Al-5Cu Alloy Using a Taguchi-Fuzzy Based Approach. Journal of Engineering Science and Technology Review, 7, 217-222. 